\title{
A Framework for the Deployment of the National Identification Number for Patients with Health Related Issues
}

\author{
Onwobi , G. \& Marwa, H. \\ Department of Computer Science \\ National Open University of Nigeria \\ Abuja, FCT, Nigeria \\ E-mail: gonwodi@noun.edu.ng
}

\begin{abstract}
Access to appropriate, credible and timely medical information is essential to save lives in the instance of accident and emergency. It is however saddening that many developing countries, especially in sub-Saharan Africa, have low or no access to information on health status talk more of coupling it to a national Identity. The National Identity Management commission was set up in 2007 to establish, own, operate, maintain and manage the national identity database in Nigeria. It carries information about the person, which is name, surname, state of origin, local government area, date of birth, height. The National Identity card carries a unique identification number that identifies each person. The Nigerian health care system has not been able to benefit from the many advantages of the national identity management. The advent of internet has made it possible to come up with a way in which the problem of computerizing medical status record effectively and sharing it can be solved. In this proposed system, an application will be developed to use National Identity Number (NIN) as an index to access the health record of a patient who in the instance of accident/emergency may be incapacitated, this will help in administering the right drug to the patient. It would serve important national interests and it is believed that the implementation of this system will have a dramatic prompt impact on the overall quality of healthcare delivery in Nigeria especially during emergency.
\end{abstract}

Keywords: Framework, Deployment, National Identification Number (NIN), Patients, Health, Emergencies, Healthcare. Journal Reference Format:

Onwobi , G. \& Marwa, H. (2019): A Framework for the Deployment of the National Identification Number for Patients with Health Related Issues. Journal of Behavioural Informatics, Social-Cultural and Development Research. Vol. 5 . No. 3, Pp 63-70. www.isteams/behavioralinformaticsjournal. Article DOI No - dx.doi.org/10.22624/AIMS/BHI/N5N3P7

\section{INTRODUCTION}

Identification is crucial for the efficient and effective delivery of health services and public health management and is therefore instrumental for achieving Sustainable Development Goal. Health practitioners need to know a patient's identity to access relevant medical and treatment histories and ensure that they are giving consistent and appropriate care. Patients also need documentation to prove enrollment in insurance programs or other safety nets that cover medical expenses. Administrators and researchers need a unique patient identifier to be able to aggregate records and share data between separate health databases (e.g., health information systems) in order to generate statistics and other data for planning, evaluation, emergency response, and improved treatments and disease management. Health insurers need to be able to identify patients to ensure that those for whom claims are submitted are actually insured and to facilitate the adjudication of claims based on the patient's history. 
A secure, inclusive, and responsible method of uniquely identifying and authenticating healthcare users over time and across facilities is central to each of these needs and the goal of achieving universal healthcare. In many countries including Nigeria, however, patient identification and information systems have historically been weak. Hospital and clinic records are often paper based, or (where digital) have stand-alone information systems that cannot communicate, transfer data or records, or aggregate data between or within facilities. This reduces monitoring and planning capacity and can lead to inferior care for existing patients. Other patients including some of the estimated 1.1 billion globally who lack legal identity documents (World Bank 2017d) are unable to prove their eligibility or coverage and thus receive no services at all. Governments also face challenges extending or rationalizing health insurance programs when it is difficult to establish the identity of existing or excluded beneficiaries. As a result, healthcare providers and officials in many countries have struggled to improve public health and reach the 3.5 billion people worldwide who do not have access to quality essential health services (World Bank 2017c).

Over the past few decades, we have begun to see important reforms in the healthcare sector that have allowed countries to overcome some of these inefficiencies. This includes, for example, the increased adoption of digital information systems such as electronic health records (EHRs) and "e-Health" platforms. According to the WHO, for example, some 47 percent of countries now have an EHR system, while some 83 percent have adopted at least one mobile health ("mHealth") application (WHO 2016). These improvements are often enabled by the creation of standalone, or functional, identification systems in the health sector, such as a unique patient ID number and/or card created by the Ministry of Health or the national health insurer and used by all facilities in the country.2 Such functional identification systems offer a number of potential benefits to patients, healthcare providers, and various government ministries. By allowing for secure and accurate identification and authentication of patients and enabling information exchange, they can increase the efficiency of patient management, improve the quality of treatment, reduce administrative burdens for patients, facilitate access to insurance, reduce fraud, and improve data collection. However, functional identification systems, such as a health ID card, can be costly to operate and contribute to a proliferation of sector-specific IDs and databases that may be non-interoperable and burdensome to users.

Aside emergency, integrating a national ID system into the health sector may improve patient management, insurance administration, and data collection for national health policy and decision. Adopting the country's national electronic identity document (eID) as a unique patient identifier will increase the efficiency and accuracy of health data, reduced the administrative burden of doctors, and facilitated new services such as an e-prescription system that leverages the elD's digital signature capability. Furthermore various programs to address certain health crisis may use the national ID to uniquely identify patients and enable an advanced monitoring system that will facilitated evaluation and scale-up of health care facilities.

\section{RELATED WORKS}

\subsection{National Identification Number (NIN)}

The National Identification Number (NIN) is a set of numbers assigned to an individual upon successful enrolment. Enrolment consists of the recording of an individual's demographic data and capture of the ten (10) fingerprints, headto-shoulder facial picture and digital signature, which are all used to cross-check existing data in the National Identity Database to confirm that there is no previous entry of the same data. Once this (de-duplication) process is completed the data is then stored with a unique NIN that was assigned to it. The NIN once issued to a person cannot be used again, (that is, it cannot be issued to another person even if the previous person is dead). It is the NIN that helps to tie all records about a person in the database and is used to check the identity verified. 


\subsection{Role of National Identity Number in Health}

As an alternative to creating a health-specific functional identification system, some countries have instead opted to use existing National identification systems, such as population registers, unique identification numbers (UINs) or national ID (NID) cards, as the basis for patient identification, verification, and authentication. Leveraging a foundational system in this way may create additional benefits beyond those offered by a functional system. First, by streamlining identity management overall and eliminating health-ID specific costs, integrating a foundational system into the health sector may improve patient management, insurance administration, and data collection even more than a functional system.

\subsection{Country-Specific Experience in Estonia and Thailand}

In Estonia, for example, adopting the country's electronic identity document (eID) as a unique patient identifier has increased the efficiency and accuracy of health data, reduced the administrative burden of doctors, and facilitated new services such as an e-prescription system that leverages the elD's digital signature capability. In Botswana, various programs to address the HIVIAIDs crisis have used the national ID to uniquely identify patients and enable an advanced monitoring system that has increased patient retention and facilitated evaluation and scale-up. Second, by using a National identifier shared with other systems e.g., civil registration and vital statistics, etc. health systems will be interoperable with other government databases. This could facilitate, for example, easier compilation of aggregate data by vital statistics offices, which can be used for planning and research, as in Korea. Similarly, in a country where multiple agencies use a common National identifier, it can be used to verify or cross-check patient attributes across systems for a variety of purposes.

In Thailand, the use of the national ID number by disparate insurance databases allowed for the rapid creation and deduplication of a universal healthcare registry. Third, these linkages can also help strengthen identification and civil registration systems by driving demand for the foundational system and creating more points of contact with individuals for updating information. For example, if a National ID card or number enables access to certain health services or insurance as in India individuals may have greater incentive to obtain it. In this way, National identification, civil registration, and health systems can be mutually reinforcing when integration between the three systems is high.

At the same time, there may also be potential drawbacks to the use of National identification systems in health. This might include, for example, risks related to privacy if sufficient legal protections and technical and administrative controls are not in place. Non-robust foundational systems or those with low coverage may also pose challenges for their integration into healthcare systems. These potential risks and benefits require careful consideration when determining how to best fulfill the identification needs of the health sector.

\subsection{Benefits of Foundational Identification in Healthcare 2.4.1 Patient Management and Treatment}

One area in which foundational identification may impact the health sector is in patient management and treatment within healthcare facilities, including hospitals, clinics, and other providers. When a patient arrives at a facility, providers need to accurately and consistently identify the individual and their relevant medical history. Without a records system that uniquely identifies a patient, administration becomes burdensome for providers and clients, requiring duplicate paperwork for each new visit that may be incomplete or inaccurate. This is particularly problematic for certain illnesses such as HIVIAIDS and tuberculosis and vaccinations that require multiple visits and adherence to established protocols (UNAIDS 2014). Furthermore, if patient ID systems exist but are not shared across facilities (e.g., if each hospital maintains its own, non-interoperable system), it may be difficult for individuals to seek care at multiple or new locations, decreasing access to and continuity of care. 
The ability to uniquely identify patients across healthcare facilities can therefore improve administration, patient management, and the quality of care by ensuring that individuals can be repeatedly and correctly identified when accessing services throughout the country (UNAIDS 2014, WHO 2012, WHO 2017a). When combined the system is implemented, a unique identifier facilitates a longitudinal history for each patient, including health status, diagnoses, test results, treatments, and outcomes over time. This reduces administrative duplication, wasted resources, and potentially dangerous errors in medications, transfusions, and testing (WHO 2007). In particular, treatment and administrative-level benefits of using unique identifiers can include (WHO 2017a):

* $f$. Ensuring accurate and timely information from multiple sources for diagnosis

* and treatment

* $f$. Improving linkages between testing and treatment during emergency

* $f$. Continuity and transferability of care when people across different facilities

* $f$. Increasing patient retention and follow-up care

* $f$. Reducing duplication of health records for the same individual

* $f$. Reducing waste and errors in diagnostic testing, medication, and treatment

Beyond this, longitudinal patient data are needed to aggregate reliable statistics on health services and outcomes over time. Such data are vital for research on the effectiveness of facilities and treatments, timely responses to public health crises, and the efficient allocation of resources (OECD 2015a, WHO 2012). This has direct benefits for Ministries of Health and Planning, and indirect benefits for healthcare providers and individuals, including by improving health outcomes and the performance of healthcare systems (OECD 2015a). While the above benefits can be achieved with the adoption of a unique identifier specific to a program or the broader healthcare system (i.e., a functional system), using an existing National identifier may offer additional benefits, including improved linkages between health and other services (e.g., social protection) that also rely on the foundational system, the technological sustainability of the system, further cost savings and increased efficiency, and more accurate data and statistics (WHO 2017a). This is particularly the case when the foundational system in question is digital, rather than paper-based. In Estonia, for example, integration between the national eID and healthcare system have limited the administrative burden on doctors, automated data collection efforts, facilitated easy identification of families for health insurance, and facilitated the adoption of an e-prescription system backed by the elD's digital signature capability. In Botswana, using the national ID number as a unique patient identifier has improved patient follow-up and retention in HIVIAIDS treatment programs

\subsection{Insurance and Benefits Programs}

Unique identification, a method of verifying or authenticating individuals, and the ability to aggregate individual-level data are also important for insurance and benefits programs within the healthcare system. In order to access health facilities or treatments, individuals in many countries must be able to prove that they are covered by insurance or another entitlement; failure to provide appropriate documentation may exclude them from services. Similarly, where identification of beneficiaries is weak, insurance and benefits providers may see higher instances of fraud. And where health information systems are fragmented and patients seek care at multiple facilities, there may be instances of double charging, double payment, or patients not being properly reimbursed (WHO 2017a, 2017b).

Importantly, health financing and insurance schemes also need complete and accurate records on service usage and data on system performance inorder to correctly bill patients and care providers and to inform budgeting and management decisions. With many countries seeking to scale their health systems and achieve universal coverage, we have seen a proliferation of new insurance schemes. Integrating a foundational identifier into such insurance programs has the potential to improve their effectiveness and efficiency while increasing inclusion. In Thailand, for example, the national population registry serves as the baseline list of beneficiaries for the universal healthcare scheme, allowing for rapid coverage and eliminating the need for a duplicative enrollment campaign. 
In Estonia, the linkage between the country's health information system and population register underpinned by its unique eID and X-Road integration layer has enabled every child to be automatically listed as a beneficiary in the health insurance fund from birth (World Bank 2015a). Furthermore, Estonia's e-Services infrastructure allows patients and providers to instantly check insurance coverage online using their national elD.

\section{STATEMENT OF THE PROBLEM}

Throughout the health-care industry, the failure to correctly diagnose patients continues to result in medication errors, transfusion errors, testing errors, among others. Certain drugs cannot be administered to certain people even in the case of accident/emergency because of their health history. Running and waiting for tests result at such times too may be risky, this is where the proposed app will be handy. Furthermore, In Nigeria today, it is difficult to know the precise record of people living with certain sort of ailments and that affects policy and planning in health sector. Attaching a citizen's health status to NIN will not only assist in prompt health care delivery but also assist the authorities in national planning, research and policy making.

\subsection{Research Thrust}

The thrust of this research is to investigate the challenges with the current operations of the NIN and initiate a framework for the deployment of the national identification number for patients with health related issues.

\subsection{Research Methodology}

The research work will be conducted by using different sources of relevant data for research. The requirements needed for the development of this application will be gotten by a review of existing systems. it will also be designed showing all the different functions that will be performed by using UML diagrams like use cases, class diagrams, etc. The implementation of the application can now be done with Javascript, PHP, and the database management will be implemented with MySQL database. The system will later on be evaluated by making use of feedbacks and reports from relevant users.

\subsection{Significance of the Study}

The significance of this study includes: ease of patient data sharing, injury/illness prevention, better training for paramedics, Review of clinical standards, better research options for pre-hospital care and design of future treatment

\section{RESULTS}

The findings made in this research informs on how to improve on treating health emergency by linking patient's medical history to NIN in Nigeria. These findings which are related to the study objectives and research questions are as follows;

- The study shows that $47(94 \%)$ of the respondents 'strongly agree' that It's important to have a patient's medical history. $2(4 \%)$ of the respondents are 'undecided', while $1(2 \%)$ of the respondent 'agree'. This implies that majority of the respondents that participated in the research survey 'strongly agree' that it is important to have a patient's medical history. Hence, The researcher was able to find out that Patient's Medical History is Important in treating health emergency

- The study shows that $48(96 \%)$ of the respondents 'strongly agree' that the Patient's medical history helps in tailoring treatment for a particular patient. $1(2 \%)$ of the respondents 'agree' while another $1(2 \%)$ of the respondents are 'undecided'. This implies that majority of the respondents that participated in the research survey 'strongly agree' that the Patient's medical history helps in tailoring treatment for the particular patient. Hence, Patient's Medical History helps in tailoring treatment for the particular patient. 
- The study shows that 47 (94\%) of the respondents 'strongly agree', 2 (4\%) are 'undecided' while $1(2 \%)$ 'agree' that access to medical history during emergencies can make a difference in the lives of patients. This implies that majority of the respondents strongly agree that access to medical history during emergencies can make a difference in the lives of patients. Hence, access to medical history during emergencies makes a significant difference in the lives of patients.

\section{CONCLUDING REMARKS}

We have been able to establish in this discourse that the Nigerian health care system has not been able to benefit from the many advantages of the national identity management. The advent of internet has made it possible to come up with a way in which the problem of computerizing medical status record effectively and sharing it can be solved. In this proposed system, an application will be developed to use National Identity Number (NIN) as an index to access the health record of a patient who in the instance of accident/emergency may be incapacitated, this will help in administering the right drug to the patient.

\section{REFERENCES}

1. Adebayo. D., Basquill. C., Aderemi A, V., Thompson. A. Y., \& Obi. F. (2015). An estimate of the prevalence of hypertension in Nigeria. Journal of Hypertension (Vol. 33, pg. 230-242)

2. American College of Allergy, Asthma \& Immunology. (2018). Anaphylaxis. https://acaai.org/allergies/anaphylaxis

3. Bhowmik. D., Kumar. S., Umadevi. M. (2012). Allergy- symptoms, Diagnosis, Treatment and Management. PharmaJournal (Vol. 13, Pg. 17-40)

4. Cancer Treatment Centers of America. (2020). Cancer type. https://www.cancercenter.com/cancer-types

5. Channels Television. (2019). FRSC Records 9,698 Accidents, 4,737 Deaths on 2019. Retrieved from: https://www.channelstv.com/2019/12/19/frsc-records-9-698-accidents-4737-deaths-in-2019/

6. Chukwuonye. I.I., Ogah. O.S., Anyabolu. E. N., Ohagwu. K. A., Nwabuko. O.C., Onwuchekwa. U., Chukwuonye. M. E., Obi. E. C., \& Oviasu. E. (2018). Prevalence of chronic kidney disease in Nigeria: systematic review of population-based studies. International Journal of Nephrology and Reno vascular diseases (Vol. 11, pg. 165-172).

7. Cochran. W. G. (1977). Sampling techniques. John Wiley \& Sons publishing. New York

8. Crews. D. C., Bello. A, K., \& Saadi. G. (2019). Burden access, and disparities in kidney diseases. Kidney International Reports, National Institute of Health, US National Library of Medicine.

9. Debjit. B., Kumar. K. P., \& Umadevi. M. (2012). Allegy - Symtoms, Diagnosis, Treatment and Management.http://www.thepharmajournal.com/archives/2012/vol1issue3/PartA/3.pdf. The Pharmajournal (Vol. 1, Pg. 16-29)

10. Doupi, P., Renko, E., Giest, S., Heywood, J., \& Dumortier, J. (2010). eHealth Strategies: Country Brief: Estonia. Brussels: European Commission Durotolu. A.O. (2001). Educational management, theories, primciples and practices. Festus Digital Prints, Abuja.

11. Egbi, O. G., Okafor, U. H., Miebodei, K. E., Kasia, B. E., Kunle-Oluwu. O. E., \& Unuigbe E. I. (2014). Prevalence and correlates of chronic kidney disease among civil servants in Bayelsa state, Nigeria. Nigerian Journal of Clinical Practice (Vol.17, pp. 602-607)

12. Fasanmade. O. A., \& Dagogo-Jack, S. (2015). Diabetes Care in Nigeria. Annuals of Global Health (Vol. 81, Pg. 821-829) 
13. Farahani, M., Vable, A., Lebelonyane, R., Seipone, K., Anderson. M., Avalos. A., Chadborn. T., Tilahun. H., Roumis. D., Moeti. T., Musuka. G., Busang. L., Gaolathe. T., Malefho. K. S., \& Malink. R, (2013). Outcome of the Botswana national HIV/Aids treatment programme from 2002 to 2010. The Lancet global health (Vol. 2, Pg. 44-50)

14. Federal Ministry of Health. (2018). National Cancer Control Plan: Federal Ministry of Health 2018-2022. https://www.iccp-portal.org/system/files/plans/NCCP_Final\%20\%5B1\%5D.pdf

15. Freund. J. E., \& Williams F. J. (1982) Elementary Business Statistics: the modern approach. Prentice-Hall

16. Gelb, A. \& Clark, J. (2012) Building a Biometric National ID: Lessons for Developing countries from India's Universal Id program.

https://www.cgdev.org/sites/default/files/archive/doc/full_text/GelbClarkUID/1426583.html. Policy Paper, Centre for Global Development.

17. Glassman. A., \& Temin. M. (Eds.). (2016). Millions saved: New cases of proven success in Global Health. Washington DC: Brookings Institution Press.

18. Hanvoravongchai, P. (2013). Thailand-Health financing reform in Thailand: toward universal coverage under fiscal Constraints. Washington, CD: World Bank.

19. International Agency for Research on Cancer. (2018). Nigeria's fact sheet. https://gco.iarc.fr/today/data/factsheets/populations/566-nigeria-fact-sheets.pdf World Health Organization.

20. International Agency for Research on Cancer. (2018). Latest global cancer data; Cancer burden rises to 18.1million new cases and 9.6million cancer deaths in 2018. https://www.who.int/cancer/PRGlobocanFinal.pdf The World Health Organization.

21. International Diabetes Federation. (2020). IDF African Members; Nigeria. Retrieved from: https://idf.org/ournetwork/regions-members/africa/members/20-nigeria.html

22. International Diabetes Federation. (2020). The global impact of diabetes. https://www.diabetesatlas.org/en/

23. Jalil. Mohammed. (2013). Practical Guidelines for Conducting Research- Summarizing Good Research Practices in Line with DCED standard. https://papers.ssrn.com/sol3/papers.cfm?abstract_id=2591803

24. Joon Song, Hee, Kang, Minah, Kim, Churin, and Kim, Yeonsoo. (2016). Korea: an integrated system of civil registration and vital statistics.

http://documents.worldbank.org/curated/en/702081495191844901/pdf/115151-WP-

KoreaCRVScasestudywebversionfinalNov-PUBLIC.pdf. World Bank.

25. Khan. I. S. \&Hoque. A. S. (2015). Development of National Health Data warehouse for Data Mining. Database System Journal (Vol. 6)

26. Lai. T., Habicht. T., Kahur. K., Reinap. M., Kiivet. R., \& Ginneken E. V. (2013) Estonia Health System

Review. https://www.ncbi.nlm.nih.gov/pubmed/24334730. US National Library of Medicine, National Institute of Health (Vol. 15)

27. Meemon. N., Paek. S. C., \& Wan. T. H. (2016) Thailand's universal coverage scheme and its impact on health-seeking behaviour. US National Library of Medicine National Institute of Health (Vol. 5) https://www.ncbi.nlm.nih.gov/pmc/articles/PMC5104696/

28. Menizibeya. O. (2011). The Nigerian health care system: Need for integrating adequate medical intelligence and surveillance systems. Journal of Pharmacy and Bio Allied Sciences (Vol. 3, Pg. 470-478).

29. Metsallik. J., Ross. P., Draheim. D., \& Piho. G. (2018). Ten years of the e-Health System in Estonia. http://ceur-ws.org/Nol-2336/MMHS2018_invited.pdf. Department of Health Technologies, Tallinn University of Technology.

30. Michal. J. C., Schmider. E. A., Luda. B., Daniel. J. M., Rivera. A., Milena. A. (2018). The role of digital identification for healthcare: The emerging use cases. The World Bank 
31. Mill, Raul. (2015). Estonian Health Information System. https://na.eventscloud.com/file_uploads/2ce7bea5573a7aab89b02ce84aa5c308_mill_EstonianNationalHeal thInformationSystem.pdf. Ministry of Health of the Republic of Latvia.

32. Mills. S., Lee. J. K., Rassekh. B. M., Kodelja. M. Z., Bae. G., Kang. M., Pannarunothai. S., \& Kijsanayotin. B. (2019). Unique health identifiers for universal health coverage. Journal of Health, Population and Nutrition 38

33. Narayan. K. M., Zhang. P., Kanaya. A. M., Williams. D. E., Engelgau. M. M., Imperatore G., Ramachandran. D. T., Jamison. D. T., Breman. J. G., Measham. R. A., Alleyne. G., Claeson. M., Evans. D. B., Jha. P., Mills. A., \& Musgrove. P. (2013). Diabetes: the pandemic and potential solutions. National Library of Medicine. Disease Control Priorities in Developing Countries. $2^{\text {nd }}$ edition. Washington (DC). The World Bank

34. National health Insurance Scheme. (2020). NHIS operational Guidelines pdf. www.nhis.gov.ng

35. National Identity Management Commission (NIMC). (2020). About the NIN. https://www.nimc.gov.ng/about$\operatorname{nin} /$

36. National Kidney Foundation. (2020). About chronic kidney diseases: symptoms and causes. https://www.kidney.org/atoz/content/about-chronic-kidney-disease

37. National Kidney Foundation (2020). What is Glomerulonephritis? https://www.kidney.org/atoz/content/glomerul

38. Neter. J., Kutner. M., Nachtsheim. C., Wasserman. W. (1996). In: Applied Linear Statistical Models. Irwin, Chicago (Pg. 958-1010).

39. Organization for Economic Co-operation and development (OECD). (2015a). Data-Driven Innovation: Big Data for Growth and Well-Being. Paris: OECD Publishing.

40. Osakwe, F. (2020, March 9). 25 million Nigerians have kidney failure, says Nephrologists. The Guardian https://guardian.ng/news/25m-nigerians-have-kidney-failure-says-nephrologists/

41. Schiffman. D. J., Paul G. F., \& Gibbs. P. (2015). Early Detection of Cancer: Past. Present and future. National Library of medicine

42. The Nation Newspaper. (2020). Understanding emergency care in hospitals https://thenationonlineng.net/understanding-emergency-care-in-hospitals/

43. The Gazette of India. (2017). Part II-Section 3, March 2017. Government of India

44. The World Bank. (2020). The Role of Digital Identification For Healthcare: Thailand.http://pubdocs.worldbank.org/en/595741519657604541/DigitalldentificationHealthcareReportFinal.pdf

45. The World Health Organization. (2016). Global Report on Diabetes. https://apps.who.int/iris/rest/bitstreams/909883/retrieve. WHO Library Catalogue.

46. UNAIDS. (2009). Developing and Using Individual Identifiers for the Provision of Health Services including HIV. Proceedings from a Workshop. Switzerland.

47. UNAIDS (Joint United Nations Programme on HIVIAIDS). (2014). Global Aids response progress reporting 2014. https://www.unaids.org/sites/default/files/media_asset/GARPR_2014_guidelines_en_0.pdf

48. World Health Organization. (2012). Management of Patient Information: Trends and Challenges in Member States. Global Observatory for e-Health series. Vol 6.

49. World Heart Foundation. (2020). Different heart diseases https://www.world-heartfoundation.org/resources/different-heart-diseases/

50. World Health Organization. (2020). Cancer. https://www.who.int/health-topics/cancer\#tab=tab_1

51. World Bank. (2017a). The principles on Identification for Sustainably Development: Towards the Digital Age. http://documents.worldbank.org/curated/en/213581486378184357/pdf/Principles-on-identification-forsustainable-development-toward-the-digital-age.pdf 